\title{
Factors and Minimal Subsidy Associated with Tea Farmers' Willingness to Adopt Ecological Pest Management
}

\author{
Rongrong Zheng ${ }^{1,2}$, Jiasui Zhan ${ }^{1,3}$, Luxing Liu ${ }^{2}$, Yanli Ma ${ }^{1}$, Zishuai Wang ${ }^{1}$, Lianhui Xie ${ }^{1, *}$ and \\ Dunchun $\mathrm{He}^{1, *}$ \\ 1 Fujian Key Lab of Plant Virology, Institute of Plant Virology, Fujian Agriculture and Forestry University, \\ Fuzhou 350002, China; zhengrr@fafu.edu.cn (R.Z.); jiasui.zhan@fafu.edu.cn (J.Z.); mayl@fafu.edu.cn (Y.M.); \\ wangzs@fafu.edu.cn (Z.W.) \\ 2 Anxi College of Tea Science, Fujian Agriculture and Forestry University, Quanzhou 362406, China; \\ luxingLiu@fafu.edu.cn \\ 3 Department of Forest Mycology and Plant Pathology, Swedish University of Agricultural Sciences, \\ 75007 Uppsala, Sweden \\ * Correspondence: xielh@fafu.edu.cn (L.X.); hedc@fafu.edu.cn (D.H.)
}

Received: 6 October 2019; Accepted: 3 November 2019; Published: 6 November 2019

\begin{abstract}
Scientific assessment related to the externalities of the tea ecological pest management (TEPM) system that can affect socio-economic development and ecological benefits is important to the sustainable development of the tea industry. This paper used the contingent valuation method to evaluate the externalities associated with TEPM and the factors affecting its adoption by farmers through survey data collected from Anxi county, Fujian province, China. The results showed that the positive externalities, which were not internalized (embodied in price), affected the willingness of tea farmers to adopt TEPM. The willingness to accept a subsidy for adopting the TEPM system was significantly affected by the individual tea farmer's age, education level, income, size of plantation, knowledge of human health and risk preference. The compensation threshold of externalities for TEPM was 5668.80 yuan per hectare per year. It is suggested that the government should adopt this threshold as a minimum subsidy to mitigate information asymmetry in two markets, namely ecological management technology and trading between suppliers and buyers of tea products. Finally, production stability and improved price for high quality tea resulting from healthy ecology in TEPM could enhance positive externalities. This coupled with other benefits, such as a reduction in the amount of resources spent on pesticides, could result in governmental subsidies for TEPM being gradually reduced over time.
\end{abstract}

Keywords: tea ecological pest management (TEPM); contingent valuation method (CVM); externalities; risk preference; impact factors

\section{Introduction}

To prevent yield losses due to pests, most tea farmers rely on heavy application of chemical pesticides but usually use them improperly, e.g., using the wrong type of pesticide or applying them at the wrong time, frequency or dose. These practices can not only lead to the evolution of pesticide resistance and cost tea farmers more, but may also give rise to outbreaks of minor non-target pests. The resultant increases in management costs and secondary epidemic risks have reduced the direct benefits of pest management and farmers' enthusiasm for growing tea [1]. Simultaneously, the negative externalities of managing pests, including toxicity to humans and animals, excessive pesticide residues in tea production, reductions in biodiversity and environmental pollution, have increased due to 
excess pesticide use [1,2]. To counter these impacts, sustainable tea pest management should focus on an ecological approach, i.e., tea ecological pest management (TEPM). The core of TEPM is the use of ecological and evolutionary principles to maximize the regulatory functions of nature by creating environmental conditions favorable for the growth and development of tea plants but adverse conditions for pests [1]. TEPM not only can maintain functional ecologies and biodiversity to ensure the quality and quantity of tea produced, but also reduce environmental pollution and associated hazards to humans and animals [2], thereby optimizing ecological, social and economic benefits.

The literature suggested that adopting a TEPM system with highly positive environmental and social externalities (public benefits) and private economic benefits would mitigate the trade-off between the short term economic benefits of increased tea production through the use of chemical pesticides and long-term losses of ecosystem services [3]. However, the long-term benefits regarding the use of TEPM were not included in the income estimation [4]. The inclusion of this externality in the calculation of economic return is highly likely to affect the plant protection strategies that tea farmers choose to use. Policy-makers in the area of tea pest management need to understand the full benefits (including non-market benefits) that they can expect from their policy, which favor developing an effective policy program. Since externalities were not priced using traditional market economics, most scholars used a hypothetical market evaluation method to investigate them [5]. One commonly used market-based valuation method is the contingent valuation method (CVM), whereby farmers are approached directly to determine their willingness to accept (WTA) a subsidy for non-market products or services [6]. This method has been used to evaluate the externalities of farmlands, wetlands and oceans [7-9] and can also be used to evaluate the externality of a TEPM system.

As the world's economy grows, the increasing demand for safe, high quality foods incentivizes farmers to produce safe agricultural products with low chemical residues using ecological approaches to manage pests $[10,11]$. Tea, with a production area of 40,000 ha annually, is one of the main industries in Anxi County, Fujian Province, China. In 2016, 68,500 tonnes of tea was produced in Anxi county, 17,000 tonnes of which was exported. This accounted for $2.96 \%$ and $4.78 \%$ of Chinese tea production and exports, respectively. Over $70 \%$ of the farmers of the county worked in the tea industry with $56 \%$ relying on it as their main source of income [12-14]. The goals of the current study were: (1) To determine the main factors influencing a farmer's willingness to accept a subsidy for the implementation of a TEPM system in the region, (2) to estimate the compensation threshold necessary for TEPM and (3) to provide some strategies for local policy makers to increase benefits derived from tea plantation and to promote the application of TEPM.

\section{Material and Methods}

\subsection{Comparison between Tea Conventional Pest Management and TEPM}

Tea conventional pest management (TCPM) mainly focused on pest elimination, which could increase costs and bring many negative externalities. In contrast, the TEPM system was based on the interaction between a tea population with abiotic and biotic factors to minimize the adverse environmental impacts of pesticides using ecological and evolutionary principles. This maximized the regulatory functions of nature, which involved integrating multiple suitable control methods and was guided by a comprehensive understanding of ecology and economics [1]. The TEPM system includes three main components: (1) Dynamic and integrated management approaches of inputs, i.e., organic fertilizers, pheromone for insect trapping and bio-pesticides; (2) temporal and spatial deployment of tea garden management, such as alternating harvests, reduced population density and using tall tea trees; and (3) increasing the heterogeneity of tea gardens through intercropping with green manure crops, variety mixture and/or planting other trees. The main comparisons between TEPM and TCPM are described in Table 1. 
Table 1. Comparisons between tea ecological pest management (TEPM) and tea conventional pest management (TCPM).

\begin{tabular}{cll}
\hline & \multicolumn{1}{c}{ TEPM } & \multicolumn{1}{c}{ TCPM } \\
\hline Aim & $\begin{array}{l}\text { Improving health conditions of tea } \\
\text { populations in agro-ecosystems }\end{array}$ & Eliminating pests \\
& $\begin{array}{l}\text { Maximizing the regulatory } \\
\text { functions of nature through the } \\
\text { balanced application of resistance, } \\
\text { avoidance, elimination and } \\
\text { remedy strategies }\end{array}$ & Utilizing chemical measures \\
\hline Key technology & $\begin{array}{l}\text { Cultivating diversified trees, } \\
\text { intercropping soybeans and } \\
\text { peanuts crops, keeping grasses on } \\
\text { hillsides, utilizing organic } \\
\text { fertilizer, pest biological and } \\
\text { agricultural management }\end{array}$ & $\begin{array}{l}\text { Using chemical pesticides, } \\
\text { herbicide and fertilizer, no grass, } \\
\text { simplified cultivating }\end{array}$ \\
& $\begin{array}{l}\text { Optimizing economic, ecological } \\
\text { and social benefits (high yield, } \\
\text { efficiency, good quality } \\
\text { and safety) }\end{array}$ & $\begin{array}{l}\text { Using maximum yield as the sole } \\
\text { target, thereby allowing many } \\
\text { unnecessary and negative effects } \\
\text { to affect the environment } \\
\text { and society }\end{array}$ \\
\hline
\end{tabular}

\subsection{Survey Area}

The survey covered 10 main production towns (Longmen, Xiping, Huqiu, Gande, Jiandou, Daping, Longjuan, Changken, Xianghua and Taozhou) located in Anxi county in the south of Fujian province, China $\left(117^{\circ} 36^{\prime}-118^{\circ} 17^{\prime}\right.$ E, $\left.24^{\circ} 50^{\prime}-25^{\circ} 26^{\prime} \mathrm{N}\right)$ (Figure 1). The county has 305,730 ha of arable land and an average annual rainfall of approximately $1700 \mathrm{~mm}$ [14].
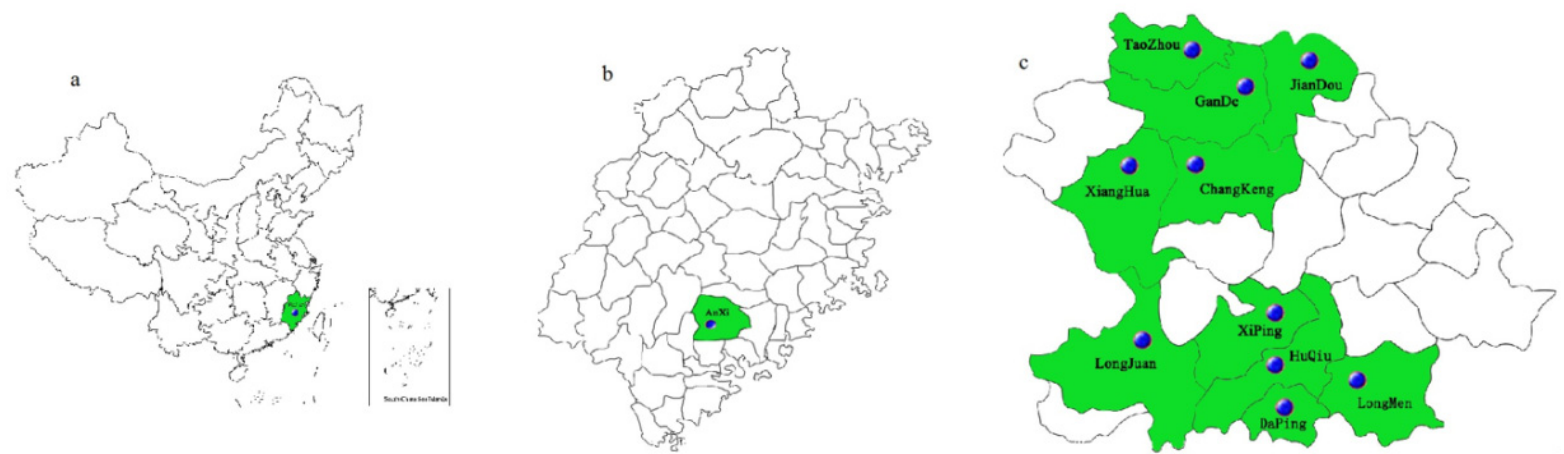

Figure 1. Map showing the geographical distribution of the ten main tea production towns of the survey. Adobe Illustrator Artwork 17.0 software was used to create the map. (a) Location of Fujian province in China. (b) Location of Anxi county in Fujian province. (c) The ten towns in Anxi county.

\subsection{Survey Design}

To obtain the direct information needed to conduct a contingency valuation method, a direct survey involving face-to-face interviews with growers was conducted. All participants gave written informed consent in accordance with the procedures of the Committee on Activities Involving Human Subjects of Anxi College of Tea Science, which approved this study. The study was conducted via a two-step process involving preliminary and formal investigations in July 2016 [9,15]. Farmers were asked questions concerning the methods they employed to manage pests and were told what TEPM was and what benefits it might provide. The willingness of farmers to accept a subsidy for adopting a TEPM system was assessed through an interview at the beginning of the preliminary investigations. 
The questionnaire that formed the core of the formal investigation was carefully designed according to the results obtained from the preliminary investigation.

The questionnaire of the formal investigation consisted of three parts (see supplemental file). Part 1 comprehensively introduced the concepts of the tea ecological pest management system and the main tea pests using colorful pictures. This information was used to estimate the incidence of different pests and current approaches to control them [7-9]. Part 2 consisted of four components: (1) The farmer's personal information (i.e., age, income and education level); (2) the size of the tea plantation; (3) the farmer's knowledge of environmental conservation and human health, which was used as an indicator of a farmer's awareness level regarding the health benefits of TEPM $(1=$ bare understanding, $2=$ slight understanding, $3=$ general understanding, $4=$ deep understanding, $5=$ complete understanding) and risk preference ( 1 = very low, $2=$ low, $3=$ medium, $4=$ high, $5=$ very high); and (4) environmental factors (tea plantation soils, altitude and climate). Part 3 consisted of CVM questions to estimate a farmer's willingness to implement a TEPM system in exchange for a subsidy.

\subsection{The Valuation Method}

The double-bounded dichotomous CVM, which is suitable for estimating public goods lacking an actual or substitute market, is one of the most widely used methods for ecosystem service value assessment $[16,17]$. Hence, it can also be used to assess the externalities of environmental management. Positive externalities of the TEPM system also pertain to a type of public goods externality, which includes direct and indirect benefits regarding ecological and social gain [18]. Compared to the single-bounded CVM, the double-bounded dichotomous CVM enabled a better understanding of a farmer's willingness to accept a subsidy for implementing TEPM control measures and improved the accuracy of the WTA a subsidy estimates $[19,20]$.

The survey goal was to elicit what farmers in Anxi county, were willing to accept a subsidy for the TEPM system. Questionnaires asked about tea farmers' WTA a subsidy for ecological pest management in two phases (Tables 2 and 3). The first step asked whether the farmer was willing to adopt ecological management principles for tea production. If the response was negative then the reasons for the decision were asked. If the answer was positive, the farmer was asked to make a sequence of two bids as to what subsidy was required in the second phase. In this phase, we asked double-bounded dichotomous choice (DBDC) questions to elicit the individual farmer's WTA a subsidy.

Table 2. Questions for the sample selection and the willingness to accept (WTA) a subsidy.

\begin{tabular}{|c|c|c|}
\hline Category & Questions & Answering Items \\
\hline Sample selection questions & Are you willing to adopt TEPM? & $\begin{array}{l}\text { 1. Yes, I am willing to adopt. } \\
\text { 2. No, I am unwilling to adopt. }\end{array}$ \\
\hline The WTA a subsidy elicitation questions & $\begin{array}{l}\text { If the answer of the sample } \\
\text { selection question is "Yes, I am } \\
\text { willing to adopt", we will ask } \\
\text { double-bounded dichotomous } \\
\text { choice (DBDC) questions to elicit } \\
\text { the farmers' WTA a subsidy. }\end{array}$ & \\
\hline First choice & $\begin{array}{l}\text { Are you willing to accept } \mathrm{BID}^{0} \text { for } \\
\text { the ecological management of } \\
\text { tea production? }\end{array}$ & $\begin{array}{l}\text { 1. Yes. } \\
\text { 2. No. }\end{array}$ \\
\hline Second choice & $\begin{array}{l}\text { (To those who answered 'Yes') Are } \\
\text { you willing to accept BID }{ }^{1} \text { for tea } \\
\text { ecological pest management? } \\
\text { (To those who answered 'No') Are } \\
\text { you willing to accept BID }{ }^{\mathrm{u}} \text { for tea } \\
\text { ecological pest management? }\end{array}$ & $\begin{array}{l}\text { 1. Yes. } \\
\text { 2. No. }\end{array}$ \\
\hline
\end{tabular}


Table 3. Sample distribution of subsidy bids and their willingness to accept (WTA) a subsidy.

\begin{tabular}{cccccccc}
\hline Item & $\mathbf{1}$ & $\mathbf{2}$ & $\mathbf{3}$ & $\mathbf{4}$ & $\mathbf{5}$ & $\mathbf{6}$ & $\mathbf{7}$ \\
\hline BID $^{0}$ (Initial bid) (yuan/ha/yr) & 3000 & 3750 & 4500 & 5250 & 6000 & 6750 & 7500 \\
BID $^{\text {l } \text { Lower bid) (yuan/ha/yr) }}$ & 2250 & 3000 & 3750 & 4500 & 5250 & 6000 & 6750 \\
BID $^{\text {u }}$ (Higher bid) (yuan/ha/yr) & 3750 & 4500 & 5250 & 6000 & 6750 & 7500 & 8250 \\
Yes, Yes (\%) & 8.47 & 23.73 & 7.55 & 28.57 & 37.34 & 70.59 & 67.21 \\
Yes, No (\%) & 10.17 & 32.2 & 16.98 & 33.33 & 28.3 & 15.69 & 26.23 \\
No, Yes (\%) & 33.9 & 16.95 & 24.53 & 20.64 & 15.09 & 5.88 & 0 \\
No, No (\%) & 47.46 & 27.12 & 50.94 & 17.46 & 18.87 & 7.84 & 6.56 \\
\hline
\end{tabular}

The DBDC contained two questions: First, are you willing to undertake the tea pest ecological management? Second, are you willing to accept a subsidy of BID ${ }^{0}$ for TEPM? If the answer was 'Yes' then a lower value second round bid ( $\mathrm{BID}^{1}$, randomly assigned from the remaining possible bid values) is made. If the answer was ' $\mathrm{No}^{\prime}$, we repeated the question with a higher bid (BID'). Based on the results of the preliminary investigations, seven different initial bids (BID ${ }^{0}: 3000,3750,4500,5250,6000$, 6750 and 7500 yuan/ha/yr) for the subsidy of TEPM at each sampling point were determined to measure the farmer's WTA a subsidy. Farmers were asked whether they accepted the initial randomly-selected bid or not. If they accepted, they were asked to answer to the same question but with a lower bid. In cases where the farmer did not accept the bid, the same question was repeated but with a higher bid offer. Therefore, there were four categories of response to the double-bounded dichotomous choice (DBDC) questions: (yes, yes), (yes, no), (no, yes) and (no, no).

The probability of each of the four results was evaluated by the following logistic function:

$$
\begin{aligned}
& P_{i}(y y)=1-1 /\left(1+\exp \left(\beta_{0}+\beta_{1} B I D_{i}^{1}+\sum r_{k} X_{k i}\right)\right. \\
& P_{i}(y n)=1 /\left(1+\exp \left(\beta_{0}+\beta_{1} B I D_{i}^{l}+\sum r_{k} X_{k i}\right)-1 /\left(1+\exp \left(\beta_{0}+\beta_{1} B I D_{i}^{0}+\sum r_{k} X_{k i}\right)\right.\right. \\
& P_{i}(n y)=1 /\left(1+\exp \left(\beta_{0}+\beta_{1} B I D_{i}^{0}+\sum r_{k} X_{k i}\right)-1 /\left(1+\exp \left(\beta_{0}+\beta_{1} B I D_{i}^{u}+\sum r_{k} X_{k i}\right)\right.\right. \\
& P_{i}(n n)=1 /\left(1+\exp \left(\beta_{0}+\beta_{1} B I D_{i}^{u}+\sum r_{k} X_{k i}\right)\right.
\end{aligned}
$$

where $i$ is the random order of those farmers who were willing to adopt TEPM $(1 \leq i \leq 399) ; P_{i}(y y)$, $P_{i}(y n), P_{i}(n y)$ and $P_{i}(n n)$ are the probabilities that the answer from farmer $i$ was (yes, yes), (yes, no), (no, yes) or (no, no) to each bid price, respectively; $B I D_{i}^{0}$ is the first bid price and $B I D_{i}^{u}$ and $B I D_{i}^{1}$ are the second bid prices, which are higher or lower than the first bid price, respectively; $\beta_{0}, \beta_{1}$ and $r_{k}$ are the estimated parameters and $X_{k i}$ represents the explanatory variables that might affect the value of the individual farmer's WTA a subsidy.

The parameters $\beta_{0}, \beta_{1}$ and $r_{k}$ were estimated using the maximum likelihood estimation (MLE). The log-likelihood function is denoted as follows:

$$
L^{d}=\sum_{i=1}^{n}\left[D_{i}^{y y} \operatorname{Ln} p_{i}(y y)+D_{i}^{y n} \operatorname{Ln} p_{i}(y n)+D_{i}^{n y} \operatorname{Ln} p_{i}(n y)+D_{i}^{n n} \operatorname{Ln} p_{i}(n n)\right]
$$

where, $D_{i}^{y y}, D_{i}^{y n}, D_{i}^{n y}$ and $D_{i}^{n n}$ are the index variables, taking the value of 1 when the answer from farmer $i$ was (yes, yes), (yes, no), (no, yes) or (no, no) to each bid price, respectively, and 0 otherwise. Following Hanemann [21], the average farmer's WTA a subsidy was estimated as the following:

$$
W T A=\beta_{0}+\sum b_{k} X_{k i}
$$

where, $b_{k}=-\left(r_{k} / \beta_{1}\right)$ are the variables of the marginal WTA a subsidy. 


\section{Results and Discussion}

\subsection{Reliability and Validity of the Questionnaire}

The formal survey was conducted with a total of 500 farmers across the ten towns of Anxi county (Figure 1). Each town was represented by 50 farmers, who were selected at random. A total of 459 questionnaires were collected by eliminating invalid responses (for example, farmers did not understand the content of the questionnaire, important information was not consistent or answers were insufficiently comprehensive). Based on the answers, a total of 399 farmers were willing to adopt TEPM, whereas 60 farmers were not willing to do so. Finally, the responses of the 399 interviewees who were willing to adopt the TEPM were determined through the use of the selection questions (Table 3).

Cronbach's Alpha was used to analyze the reliability of the questionnaire. The Cronbach's Alpha of the questionnaire was $0.704(0.7<\alpha<0.9)$ which indicated strong reliability and showed that the questionnaire data had good internal consistency.

\subsection{The Socio-Economic Characteristics}

Most of the tea farmers surveyed were middle-aged (average age $=47$ years old) with the largest proportion (35.09\%) in the 41-50 year age group. The second largest group (28.32\%) was between 31-40 years old (Table 4 ). 60.65\% of the tea farmers interviewed were men. The education level distribution was below the normal distribution but varied across the entire range with the largest proportion having only primary school or below education $(42.61 \%) ; 36.84 \%$ of the respondents were junior high school graduates, while only $4.51 \%$ held a college degree or above. The average tea plantation area was approximately 0.6 ha with a minimum of 0.07 ha and a maximum of 3.2 ha. Farmers with tea plantations ranging between 0.4 and 0.8 ha accounted for $47.62 \%$ of growers indicating that most were small-holders. The survey also showed that the mean annual income of the tea farmers was 107,000 yuan with an income distribution ranging between 15,000 yuan and 500,000 yuan. Respectively, $39.35 \%$ and $23.06 \%$ of the farmers had yearly incomes of $60,000-100,000$ yuan and $100,000-150,000$ yuan. With regard to their knowledge of environmental conservation and human health, the farmers mostly showed a general understanding or better $(\geq 3)$ accounting for $50.58 \%$ and $29.33 \%$ of individuals, respectively. Risk averse farmers made up $95.24 \%$ of the total tea farmers (including categories 1, 2 and 3 of risk preference), which indicated that most tea farmers preferred to farm the way they already did, presumably because new approaches brought uncertain impacts. 
Table 4. Information regarding the tea farmers interviewed.

\begin{tabular}{|c|c|c|c|}
\hline Variables & Category & Number of Individuals & Percentage $(\%)$ \\
\hline \multirow{5}{*}{ Age } & $\leq 30$ & 21 & 5.26 \\
\hline & $31-40$ & 113 & 28.32 \\
\hline & $41-50$ & 140 & 35.09 \\
\hline & $51-60$ & 53 & 13.28 \\
\hline & $\geq 60$ & 72 & 18.05 \\
\hline \multirow{4}{*}{ Education level } & 0 & 170 & 42.61 \\
\hline & 1 & 147 & 36.84 \\
\hline & 2 & 64 & 16.04 \\
\hline & 3 & 18 & 4.51 \\
\hline \multirow{5}{*}{ Income (yuan) } & $\leq 50,000$ & 71 & 17.79 \\
\hline & $50,000-100,000$ & 157 & 39.35 \\
\hline & $100,000-150,000$ & 92 & 23.06 \\
\hline & $150,000-200,000$ & 62 & 15.54 \\
\hline & $\geq 200,000$ & 17 & 4.26 \\
\hline \multirow{5}{*}{ Size of plantation (ha) } & $\leq 0.4$ & 102 & 25.56 \\
\hline & $0.4-0.8$ & 190 & 47.62 \\
\hline & $0.8-1$ & 71 & 17.79 \\
\hline & $1-1.5$ & 29 & 7.27 \\
\hline & $\geq 1.5$ & 7 & 1.76 \\
\hline \multirow{5}{*}{$\begin{array}{l}\text { Knowledge of environmental } \\
\text { conservation }\end{array}$} & 1 & 56 & 14.04 \\
\hline & 2 & 151 & 37.85 \\
\hline & 3 & 132 & 33.08 \\
\hline & 4 & 52 & 13.03 \\
\hline & 5 & 8 & 2 \\
\hline \multirow{5}{*}{ Knowledge of health } & 1 & 123 & 30.82 \\
\hline & 2 & 159 & 39.85 \\
\hline & 3 & 64 & 16.04 \\
\hline & 4 & 40 & 10.03 \\
\hline & 5 & 13 & 3.26 \\
\hline \multirow{5}{*}{ Risk index (I) } & 1 & 75 & 18.8 \\
\hline & 2 & 149 & 37.34 \\
\hline & 3 & 156 & 39.1 \\
\hline & 4 & 18 & 4.51 \\
\hline & 5 & 1 & 0.25 \\
\hline \multirow{7}{*}{ Accept initial bid (yuan/ha/yr) } & 3000 & 48 & 18.64 \\
\hline & 3750 & 26 & 55.93 \\
\hline & 4500 & 40 & 24.53 \\
\hline & 5250 & 24 & 61.9 \\
\hline & 6000 & 18 & 65.64 \\
\hline & 6750 & 7 & 86.28 \\
\hline & 7500 & 4 & 93.44 \\
\hline
\end{tabular}

(1) Education level: $0=$ primary school or below, $1=$ junior high school, $2=$ high school or technical secondary school and $3=$ college degree or above.

(2) Knowledge of environment conservation and health: $1=$ bare understanding, $2=$ slight understanding, $3=$ general understanding, $4=$ deep understanding and $5=$ complete understanding.

(3) Risk preference: $1=$ very low (completely risk averse), $2=$ low (highly risk averse), $3=$ medium (slightly risk averse), $4=$ high (highly risk loving) and $5=$ high (complete risk loving).

The bid value significantly impacted the willingness of tea farmers to accept a subsidy (Table 3 ). In the double-bounded dichotomous CVM, with an increase in the bid value, the proportion of farmers willing to accept a TEPM system increased in response to the initial bid (Table 3), according to the economics principle of utility [22]. The bid value of 4500 yuan was the turning point, which indicated 
that the proportion of acceptance of a bid value of 4500 yuan was lower than the bid value of 3000 (Table 3). The main reason was that the farmers' risk preference affected their WTA a subsidy (Table 4). The proportion of risk averse ( $\mathrm{I}=4$ or 5 ) farmers selected a bid value of 4500 yuan was $85.19 \%$, which was lower than the proportion of farmers who selected a bid value of 3750 yuan $(94.92 \%)$. Therefore, farmers who selected a bid value of 4500 yuan were less risk-averse and preferred to adopt the TEPM system, therefore they had a lower WTA a subsidy value.

\subsection{Reasons for Tea Farmers' Unwillingness to Adopt TEPM}

The main reasons for a lack of willingness to adopt TEPM are listed in Figure 2 with 60 the interviewed farmers being unwilling to adopt TEPM. Out of this group, 30\% thought they would receive no financial support from the government for ecological management and the low profit associated with planting tea accounted for a further $23 \%$ of responses. More concerningly, about $13 \%$ of farmers did not believe that ecological management would have any real impact, while a further $12 \%$ were unaware of ecological management. The remaining decliners were risk-averse. These factors might contribute to the unwillingness of farmers to adopt ecological management (Figure 2) suggesting that new decision-making by tea farmers could be impacted by the benefits and risks due to asymmetric information. Thus, these farmers would make decisions according to the opportunity cost and short-term economic benefits, in addition to the risks and benefits of ecological management. Risk averse farmers who lacked the ability to accept innovations were more sensitive to short-term economic returns. This resulted in the low acceptance rate among these tea farmers regarding ecological management. All of these concerns could be solved by the teamwork among government, tea farmers and technology supplies which will provide guidance related to consumers' demands and available production technologies as well as help to internalize external benefits, such as subsidies, decision making of farmers, control approaches, taxations, insurance, etc. However, with the exception of subsidies, decisions related to production, marketing strategies must be designed according to sustainable development of China.

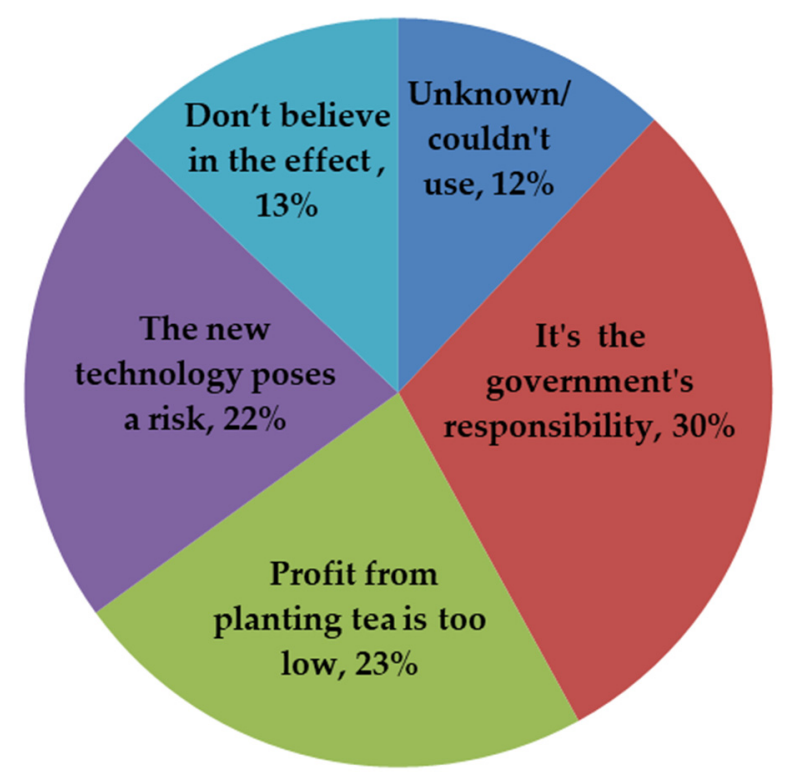

Figure 2. Reasons for unwillingness to adopt tea ecological pest management (TEPM).

\subsection{Economic Analysis of Tea Pest Management Mode}

The profit of the conventional management (TCPM) mode was 6436 yuan/ha/yr higher than the TEPM approach (Table 5). The economic input of TEPM was about 53,742 yuan/ha/yr and the economic output was $94,452 \mathrm{yuan} / \mathrm{ha} / \mathrm{yr}$, thus generating a net economic benefit for TEPM of 40,710 yuan/ha/yr. 
In contrast, the economic cost of TCPM was lower than that of TEPM, but the economic output was higher.

Table 5. Economic analysis of two tea pest management modes.

\begin{tabular}{ccc}
\hline Items & TEPM (yuan/ha/yr) & TCPM (yuan/ha/yr) \\
\hline Organic fertilizer & $3467 \pm 117$ & 0 \\
Chemical fertilizer & $6457 \pm 125$ & $19,467 \pm 772$ \\
Chemical pesticide & $1264 \pm 89$ & $3626 \pm 236$ \\
Labor (weeding, loosening, trimming, application and picking) & $32,444 \pm 244$ & $28,467 \pm 942$ \\
The cost of planting trees and intercropping peanuts or soybeans & $10,110 \pm 536$ & 0 \\
Economic input & $53,742 \pm 1001$ & $51,560 \pm 1117$ \\
Economic output & $94,452 \pm 797$ & $98,706 \pm 6223$ \\
Net profit & $40,710 \pm 1323$ & $47,146 \pm 3517$ \\
\hline
\end{tabular}

Compared with the conventional management mode, the cost increase associated with TEPM resulted mainly from the increased labor input of tea plantation management and the economic input of planting trees and intercropping peanuts and soybeans in the earlier stages. Labor was the biggest economic cost for both tea pest management modes, accounting for over $60.4 \%$ and $55.2 \%$, respectively (Table 5). There were two main reasons for this: First, it was hard to implement mechanization in the mountain regions with terraced shapes where most tea gardens were located. Second, the short harvesting period for tea leaves required a concentrated pulse of labor to pick leaves within the time of optimum maturity [3]. The second greatest economic cost of TEPM was planting trees and intercropping with peanuts or soybeans. These non-mechanized activities, which depended greatly on local farmers, were associated with a $13.97 \%$ increase in labor cost (Table 5). This gap of labor cost between the two planting modes resulted mainly from weeding ( -1600 yuan/ha/yr), loosening (-480 yuan/ha/yr), trimming (320 yuan/ha/yr), fertilizer and pesticide applications (-4640 yuan/ha/yr), planting (7040 yuan/ha/yr for three years) and rotation with soybeans or peanuts (1920 yuan/ha/yr). Thus, from an economic viewpoint, the TCPM mode was the more reasonable choice leading to about a $7.67 \%$ saving of the economic costs and consequently a $13.6 \%$ increase in net profit (Table 5).

\subsection{The Variables of Farmers' WTA Subsidy and Estimate of WTA Subsidy}

Farmers' WTA a subsidy for TEPM was correlated with age, education level, income, area of tea plantation, knowledge of human health and risk preference (Table 6). Age had a positive and significant impact on the farmers' WTA a subsidy with older farmers who had a lesser understanding of new technology and were more risk-averse having a higher WTA a subsidy value, suggesting that applicability of TEPM and national insurance would contribute greatly to future adaptation of the strategy. The education level coefficient was negative and significant at the $1 \%$ level, implying that farmers with higher education levels would be more likely to realize the importance of TEPM and have a lower WTA a subsidy value. Knowledge of environment conservation and human health were negatively and significantly associated with WTA a subsidy, suggesting that if tea farmers paid more attention to the environment and health benefits of TEPM, they would be more willing to adopt TEPM with a lower WTA a subsidy value. The negative coefficient of risk preference was significant at the 0.01 level, indicating that tea farmers who favored higher risks would be more likely to adopt a new ecological management technique. These results were consistent with findings by other researchers $[23,24]$. Finally, the study indicated that neither tea plantations area, nor income had any significant relationship with tea farmers' WTA a subsidy for ecological management. This could be due to the fact that the variables of area and income indirectly influenced farmers' WTA a subsidy. Table 6 showed that the value of the Log likelihood statistic was -486.8173 , with $p<0.01$, indicating a high significance for the model. 
Table 6. Estimate using the double-bounded dichotomous contingent valuation method (CVM) model.

\begin{tabular}{cccc}
\hline Variable & Coefficient $(\beta)$ & $\begin{array}{c}\text { Standard } \\
\text { Deviation }\end{array}$ & $p$ \\
\hline Constant & $390.29^{* * *}$ & 61.2166 & 0.000 \\
Age & $8.1286^{* * *}$ & 0.847 & 0.000 \\
Education level & $-30.9692^{* * *}$ & 11.2812 & 0.006 \\
Income & -0.1154 & 1.5889 & 0.942 \\
Area of tea plantation & -0.9035 & 2.0047 & 0.652 \\
Understanding of environment conservation & $-20.1000^{* *}$ & 10.523 & 0.056 \\
Understanding of health & $-53.4324^{* * *}$ & 10.4997 & 0.000 \\
Risk index & $-88.6346^{* * *}$ & 12.495 & 0.000 \\
Log likelihood & -486.8173 & & \\
Wald chi ${ }^{2}(7)$ & 299.85 & \\
Prob $>$ chi & & \\
Observations & 0.0000 & \\
\hline
\end{tabular}

In the estimation of the double-bounded dichotomous CVM, we excluded certain variables that were not significant. During the fitting of the regression coefficient and the average value of the variables into Formula 4, it was estimated that the annual average WTA a subsidy was $5668.8 \mathrm{yuan} / \mathrm{ha} / \mathrm{yr}$ (Table 7), suggesting that tea farmers were willing to accept this minimal subsidy of TEPM.

Table 7. Parameters estimated by the double-bounded dichotomous CVM model.

\begin{tabular}{ccccc}
\hline Value of Mean WTA Subsidy (yuan/ha/yr) & Standard Deviation & $\boldsymbol{p}$ & $\mathbf{9 5 \%}$ Confidence Interval \\
\hline 5668.8 & 18.264 & 0 & 6205.8 & 5131.8 \\
\hline
\end{tabular}

\section{Conclusions}

The positive externalities from ecological management were not internalized, which affected the adoption of ecological management by the farmers. Externalities associated with plant pest management may be positive or negative and can be divided into short- and long-term ecological, social and economic components [1]. The economic theory suggests that rational economists would not only weigh the costs and short-term economic gains, but also the risks and benefits [25]. Hence, rational tea farmers as implementers of TEPM should weigh its benefits against its costs. If the positive externalities from ecological management could not be reflected in the market price of tea, tea farmers would gain reduced benefits from the practice, with the exception of direct savings from fewer pesticide applications.

To internalize the external effects of ecological management, governments should institute a financial subsidy of more than 5668.8 yuan/ha/yr to encourage farmers to adopt this management approach, because such a financial subsidy of TEPM (5668.8 yuan/ha/yr) would be less than the direct economic loss (6437 yuan/ha/yr). The proposed financial subsidy of TEPM was found to be approximately $10.55 \%$ of the economic input and could compensate the additional input. This measure was encouraging [26], but some effective management should also be considered to improve market information symmetry. The government should aim to improve market information symmetry. In the technology (production) market, the technical system of ecological management is expected to serve tea farmers. The government should encourage the technology development of TEPM to integrate the management of major pests with ecological principles while propagating and demonstrating the values of TEPM to encourage greater adoption. This would enhance the sense of social responsibility among tea farmers while improving the efficiency of new technologies. In the tea market, in order to generate effective supply and demand, tea should require reliable certification, such as organic certification, that confers a high-quality value. Government should build supply and demand information platforms which the public could trust, in addition to improving consumers' purchasing power, which could increase the price of high-quality tea, while achieving positive externalities and 
internalizing external effects. To achieve the goal of sustainable tea management, some long-term economic and social measures, such as insurance, cooperation of industrial tea chains and improvement regarding citizens' awareness of social welfare, are needed. Many public policies can be used to internalize the externality. The government can guide tea farmers to adopt TEPM in terms of requirement guidance, technology supply, information symmetry, etc., in the long-term. However, it is difficult to prompt TEPM, because tea farmers tend to not follow governmental guidance due to the conflicts between short-term and direct economic benefits associated with producers and long-term, indirect economic benefits generated for society as a whole. Therefore, the market-based regulations including subsidies as main methods are relatively feasible at present.

Supplementary Materials: The following are available online at http://www.mdpi.com/2071-1050/11/22/6190/s1.

Author Contributions: L.X. and D.H. conceived and supervised the experiments and wrote, reviewed and edited the manuscript. R.Z. investigated and analyzed the data and wrote, reviewed and edited the manuscript. J.Z. wrote, reviewed and edited the manuscript. L.L. collected and analyzed the data. Y.M. and Z.W. conducted the investigation.

Funding: This research was funded by the Natural Science Foundation of Fujian province, China (No. 2018J01707), the project of the Ecological Civilization Research Center of Fujian's social science research base, China (No. KXJD1807A), the young and middle-aged teacher education scientific research project in Fujian province, China (No. JAS150247), the Scientific Innovation Foundation of Fujian Agriculture and Forestry University, China (No. CXZX2018100) and the Foundation of the Anxi Tea Science College of Fujian Agriculture and Forestry University, China (No. ACKY2016001).

Acknowledgments: The authors are grateful to the team of the tea industry, Anxi college of Tea Science, Fujian Agriculture and Forestry University, for their assistance with the survey and the anonymous reviewers for their valuable comments on the draft of this manuscript.

Conflicts of Interest: The authors declare no conflict of interest. The funders had no role in the design of the study, in the collection, analyses or interpretation of data, in the writing of the manuscript or in the decision to publish the results.

\section{References}

1. He, D.C.; Zhan, J.S.; Xie, L.H. Problems, challenges and future of plant disease management: From an ecological point of view. J. Integr. Agric. 2016, 15, 705-715. [CrossRef]

2. Xie, L.H. Plant protection strategy of China in the 21 century. Rev. China Agric. Sci. Technol. 2003, 5, 5-7. [CrossRef]

3. Xue, H.; Ren, X.; Li, S.; Wu, X.; Cheng, H.; Xu, B.; Gu, B.J.; Yang, G.F.; Peng, C.H.; Ge, Y.; et al. Assessment of private economic benefits and positive environmental externalities of tea plantation in China. Environ. Monit. Assess. 2013, 185, 8501-8516. [CrossRef] [PubMed]

4. Zhao, Z.H.; Reddy, G.V.P.; Hui, C.; Li, B.L. Approaches and mechanisms for ecologically based pest management across multiple scales. Agric. Ecosyst. Environ. 2016, 230, 199-209. [CrossRef]

5. Antoci, A.; Russu, P.; Ticci, E. Environmental externalities and immiserizing structural changes in an economy with heterogeneous agents. Ecol. Econ. 2012, 81, 80-91. [CrossRef]

6. Björn, S.; Svensson, M.; Schulenburg, J.M.G.V.D. Estimating a constant WTA for a QALY-A mission impossible? Eur. J. Health Econ. 2018, 3, 871-880. [CrossRef]

7. Gelo, D.; Koch, S.F. Contingent valuation of community forestry programs in Ethiopia: Controlling for preference anomalies in double-bounded CVM. Ecol. Econ. 2015, 114, 79-89. [CrossRef]

8. Yu, X.; Abler, D. The demand for food quality in rural china. Am. J. Agric. Econ. 2010, 91, 57-69. [CrossRef]

9. Jin, J.; Jiang, C.; Lun, L.I. The economic valuation of cultivated land protection: A contingent valuation study in Wenling City, China. Landsc. Urban Plan. 2013, 119, 158-164. [CrossRef]

10. Appendini, K.; Quijada, M.G. Consumption strategies in Mexican rural households: Pursuing food security with quality. Agric. Hum. Values 2016, 33, 439-454. [CrossRef]

11. Deguine, J.P.; Ferron, P.; Russell, D. Sustainable pest management for cotton production. A review. Agron. Sustain. Dev. 2008, 28, 113-137. [CrossRef]

12. Zhu, L.N. Anxi Tea Exports to Asean Market Increased Significantly. Available online: http://www.sohu. com/a/160468362_267106, (accessed on 7 July 2017). 
13. Database: The Data of Chinese Tea Production and Exports were from National Bureau of Statistics of China. Available online: http://data.stats.gov.cn/easyquery.htm?cn=C01(accessed on 12 October 2017).

14. Lin, A.H.; Gao, S.L.; Ye, N.X. Empirical study on the influencing factors of tea farmers' construction willingness for ecological tea garden-Taking Anxi county as a case. Tea Sci. Technol. 2014, 03, 54-60. [CrossRef]

15. Akram, A.A.; Olmstead, S.M. The value of household water service quality in lahore, Pakistan. Environ. Resour. Econ. 2011, 49, 173-198. [CrossRef]

16. Holt, C.A.; Laury, S.K. Risk aversion and incentive effects. Am. Econ. Rev. 2002, 92, 1644-1655. [CrossRef]

17. Chaudhry, P.; Singh, B.; Tewari, V.P. Non-market economic valuation in developing countries: Role of participant observation method in CVM analysis. J. For. Econ. 2007, 13, 259-275. [CrossRef]

18. Johnson, B.K.; Whitehead, J.C.; Mason, D.S.; Walker, G.J. Willingness to accept payment for downtown public goods generated by large, sports- anchored development projects: The CVM approach. City Cult. Soc. 2012, 3, 201-208. [CrossRef]

19. Chaudhry, P.; Tewari, V.P. A comparison between TCM and CVM in assessing the recreational use value of urban forestry. Int. For. Rev. 2010, 8, 439-448. [CrossRef]

20. Sun, C.; Nan, L.; Ouyang, X. Chinese public willingness to accept payment to avoid having nuclear power plants in the neighborhood. Sustainability 2014, 6, 7197-7223. [CrossRef]

21. Hanemann, M. Welfare evaluations in contingent valuation experiments with discrete responses. Am. J. Agric. Econ. 1984, 66, 332-341. [CrossRef]

22. Ormazabal, K.M. The law of diminishing marginal utility in alfred marshall's principles of economics. Eur. J. Hist. Econ. Thought 1995, 2, 91-126. [CrossRef]

23. Cardenas, J.C.; Carpenter, J.P. Three themes on field experiments and economic development. Res. Exp. Econ. 2005, 10, 71-123. [CrossRef]

24. Binici, T.; Koç, A.A.; Zulauf, C.R.; Bayaner, A. Risk attitudes of farmers in terms of risk aversion: A case study of Lower Seyhan Plain farmers in Adana Province, Turkey. Turk. J. Agric. For. 2003, 27, 305-312. [CrossRef]

25. Warren, M.P. Hormone therapy for menopausal symptoms: Putting benefits and risks into perspective. J. Fam. Pract. 2010, 59, 1-7. [CrossRef]

26. Bennett, M.T.; Yazhen, G.; Riccardo, S. Hungry birds and angry farmers: Using choice experiments to assess "eco-compensation" for coastal wetlands protection in China. Ecol. Econ. 2018, 154, 71-87. [CrossRef] 